\title{
A rare case of Mullerian agenesis with descent of gonads
}

\section{Saswati Tripathy*, Anjalakshi Chandrasekhar}

Department of Obstetrics \& Gynaecology, SRM Medical College Hospital \& Research Centre, Kattankulathur603203, Tamil Nadu, India

Received: 11 April 2014

Accepted: 4 May 2014

*Correspondence:

Dr. Saswati Tripathy,

E-mail: saswatitripathy@yahoo.com

(C) 2014 Tripathy S et al. This is an open-access article distributed under the terms of the Creative Commons Attribution Non-Commercial License, which permits unrestricted non-commercial use, distribution, and reproduction in any medium, provided the original work is properly cited.

\section{ABSTRACT}

Presence of ovary in inguinal hernia is a rare condition. The diagnosis is made either radiologically or laparoscopically. We report a case of primary amenorrhoea with ovarian inguinal hernia. Psychological support should be provided as a part of management.

Keywords: Inguinal hernia, Mullerian agenesis, Neovagina

\section{INTRODUCTION}

Inguinal hernia containing an ovary and fallopian tube is an extremely rare occurrence. This is commonly associated with defect in genital tract development. Ovaries ascend under the influence of developing cranial ovarian suspensory ligament. Like primordial structures in the internal genitalia, the suspensory structures show sexual dimorphism during development. Migration of ovary is a steroid hormone mediated process and cessation of migration may be regulated at receptor level.

\section{CASE REPORT}

A twenty year old female presented with complaints of abdominal pain and primary amenorrhoea. Her past history revealed that she had not attended menarche and had not any cyclical abdominal pain. The patient had undergone surgery (bilateral herniotomy) for inguinal hernia eleven years back. The reports of the past surgery revealed that the left side hernia had contained a calcified ovary with fallopian tube and was removed. Also the right side hernia contained an ovary and fallopian tube, which were normal and preserved. Her family history did not suggest any similar cases. She was a non-smoker and had no history of alcohol or any drug intake.
On examination, there were no features of hirsutism. Bilateral breasts were well developed and axillary, pubic hairs were present. Bilateral inguinal scar marks were seen in abdomen. The external genitalia were well developed. No clitoromegaly was found but vagina was absent. On rectal examination uterus could not be felt. The blood parameters were in the normal range. Ultrasound examination revealed a small uterus (measuring $2.7 \mathrm{~cm} \mathrm{x} 1.1 \mathrm{~cm}$ ) in which endometrial strip could not be made out (Figure 1a). Left ovary was not visualised but right ovary was of $4.5 \mathrm{~cm} \times 2.5 \mathrm{~cm}$ size with follicles (Figure 1b). The karyotyping showed a 46xx type which is suggestive of normal study.
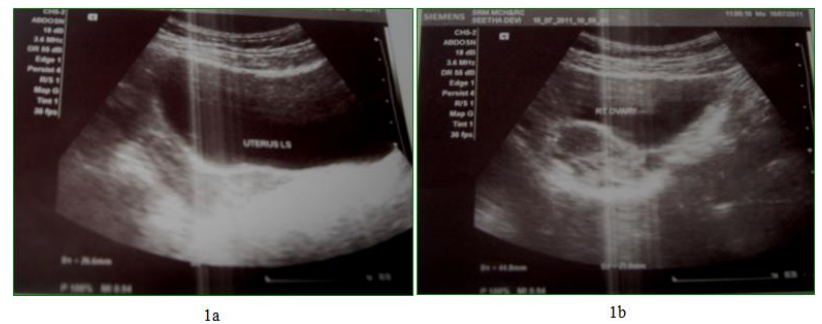

Figure 1: Pelvic ultrasound showing uterus 1(a) and right ovary with cyst (1b). 
Diagnostic laparoscopy was planned for this patient. The intraoperative findings revealed that the left fallopian tube and ovary were absent. Right of fallopian tube with ovary was present along with a nodule (Rudimentary horn of uterus which was attached to the lateral pelvic wall) (Figure 2). The pouch of Douglas was empty (Figure 3). A right ovarian cyst of $(2 \mathrm{~cm} \times 2 \mathrm{~cm})$ size was present and adhesions were seen between omentum and anterior abdominal wall in left side. The patient was managed with ovarian cystectomy with adhesiolysis and had an uneventful recovery.

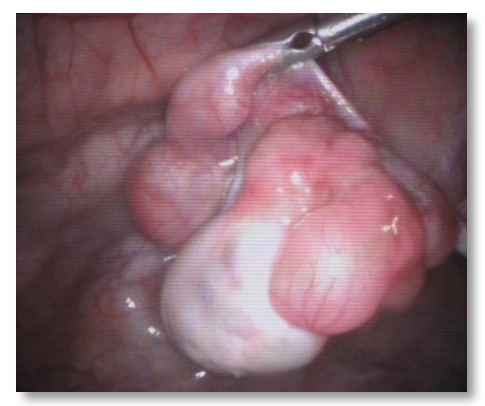

Figure 2: Laparoscopic view showing rudimentary horn of uterus with right ovary.

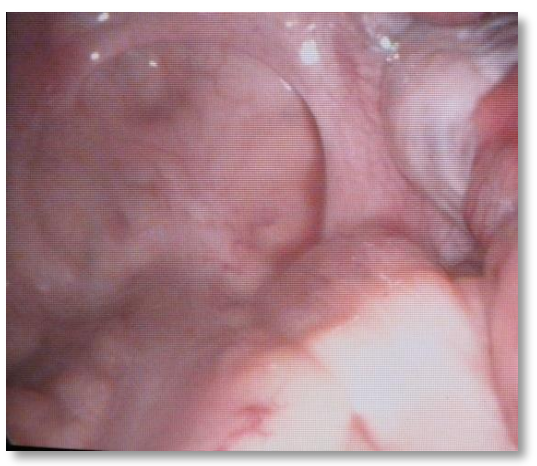

Figure 3: Laparoscopic view showing pouch of Douglas.

\section{DISCUSSION}

Mullerian agenesis with ovarian inguinal hernia is a rare entity. ${ }^{1}$ The true prevalence of this type of disorder in the reproductive age group is not known. The diagnosis is mostly made either as a part of investigation for primary amenorrhoea or the patient may present as inguinal hernia. If the ovary gets incarcerated then it becomes an emergency and needs urgent surgery. Marionkovic et al. had reported a case of prolapse irreducible ovary and had recommended urgent operative repositioning of ovary ${ }^{2}$ but Vaughn et al. had suggested laparoscopic approach to this inguinal hernia. ${ }^{3}$

The migration of gonads is controlled by multiple factors both anatomical and hormonal, which should occur in appropriate time and correct sequence. The presence of ovaries in the inguinal hernia was previously thought to be prolapse but now is assumed as descended gonads like testes. ${ }^{4}$

Our patient reported as a case of primary amenorrhoea with pain abdomen and was operated in past for inguinal hernia. But the patient was not appropriately informed. So careful evaluation and proper counselling along with surgery should be done. Our patient was informed properly and was suggested for construction of neovagina prior to her marriage.

Funding: No funding sources

Conflict of interest: None declared

Ethical approval: Not required

\section{REFERENCES}

1. Bazi T, Berjawi G, Seoud M. Inguinal ovaries associated with Mullerian agenesis: case report and review. Fertil Steril. 2006;85(5):1510.

2. Marinkovic S, Kantardzic M, Bukarica S, Grebeldinger S, Pajic M. When to operate nonreducible ovary? Med Pregl. 1998;51(1112):537-40.

3. Vaughn TC, Jones HC. Laparoscopic repair of bilateral inguinal hernias in a patient with Mullerian agenesis. Fertil Steril. 2000;73:1238.

4. Ozbey H, Ratschek M, Schimpl G, Hollwarth ME. Ovary in hernia sac: prolapsed or descended gonad? J Pediatr Surg. 1999;34(6):977-80.

DOI: $10.5455 / 2320-1770$. ijrcog20140642

Cite this article as: Tripathy S, Chandrasekhar A. A rare case of Mullerian agenesis with descent of gonads. Int J Reprod Contracept Obstet Gynecol 2014;3:475-6. 